\title{
Agôn
}

Revue des arts de la scène

Critiques | Saison 2012-2013

\section{Medea, my Mother du Theâtre-laboratoire Sfumato, mise en scène de Margarita Mladenova et Ivan Dobchev}

Le virage du Sfumato

\section{Caroline Châtelet}

\section{OpenEdition}

Journals

Édition électronique

URL : http://journals.openedition.org/agon/2674

DOI : 10.4000/agon.2674

ISSN : 1961-8581

Éditeur

Association Agôn

Référence électronique

Caroline Châtelet, « Medea, my Mother du Theâtre-laboratoire Sfumato, mise en scène de Margarita Mladenova et Ivan Dobchev », Agôn [En ligne], Critiques, mis en ligne le 09 juillet 2013, consulté le 23 septembre 2020. URL : http://journals.openedition.org/agon/2674 ; DOI : https://doi.org/10.4000/ agon. 2674

Ce document a été généré automatiquement le 23 septembre 2020

Association Agôn et les auteurs des articles 


\section{Medea, my Mother du Theâtre- laboratoire Sfumato, mise en scène de Margarita Mladenova et Ivan Dobchev}

Le virage du Sfumato

Caroline Châtelet

\section{RÉFÉRENCE}

Medea, my Mother, texte d'Ivan Dobchev et Stefan Ivanov, mise en scène d'Ivan Dobchev et Margarita Mladenova, Théâtre-laboratoire Sfumato- International Theatre Festival, Varna Summer - 5 juin 2013

http://www.theatrefest-varna.org, http://sfumato.info

\section{NOTE DE L'AUTEUR}

Présenté au Festival international de théâtre de Varna ${ }^{1}$, Medea, my Mother marque une nouvelle étape dans le travail du Théâtre-laboratoire Sfumato, qui s'essaie ici au théâtre documentaire. 


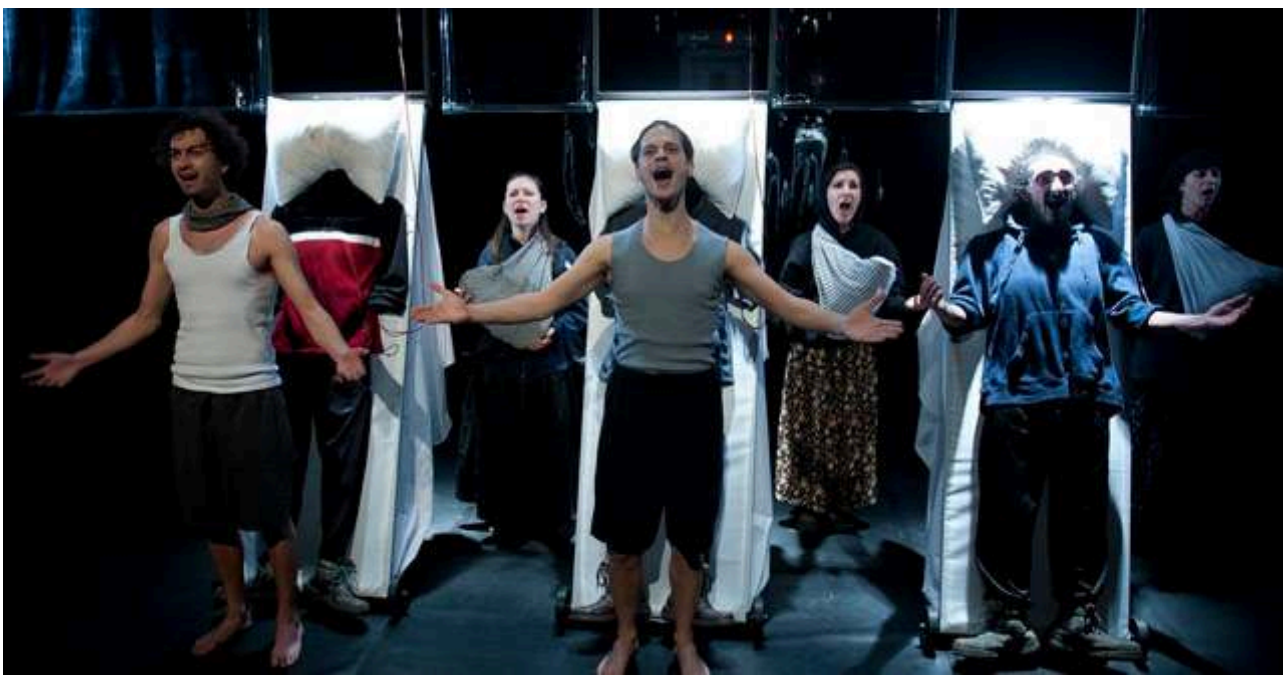

(C) Simon Varsano

1 Medea, my Mother s'ouvre sur un geste étrange, inlassablement répété durant la première séquence: à l'avant-scène, trois tziganes sont "allongés " sur des lits d'hôpitaux présentés à la verticale. Tandis qu'autour d'eux gravite un personnel médical, ils serrent le poing en cadence, se livrant successivement à un témoignage. Hermétique pour un non-autochtone, ce geste renvoie à la collecte du sang en Bulgarie: effectué le plus souvent contre rétribution, subissant le marché noir, ce «don » a pour principaux volontaires des tziganes - ces derniers ayant peu de moyens de subsistance. Derrière cette problématique spécifique, c'est toute la politique bulgare à l'égard des minorités, notamment des Roms, que Medea, my Mother dénonce violemment. Entremêlant témoignages documentaires et histoire fictive d'un homme dont la vie dépend d'une transfusion, la création ne laisse pas indifférent, tant par son interpellation sur un phénomène bulgare contemporain que par sa tentative (plus ou moins heureuse) d'approcher un théâtre documentaire.

Mais reprenons. De par son projet même, Medea, my Mother constitue un sacré virage pour le Sfumato. Car depuis sa création en 1989 par Margarita Mladenova et Ivan Dobchev, la compagnie s'est faite connaître pour son travail « autour » d'auteurs tels qu'Anton Tchekhov, Yordan Raditchkov, ou encore August Strindberg. Rien de cela ici, puisque le spectacle, co-écrit par le metteur en scène Ivan Dobchev et Stephen Ivanov auteur avec qui le sfumato collabore pour la première fois - mêle documentaire et fiction. Une hétérogénéité des paroles signalée dans l'occupation de l'espace, puisque tandis que la fiction théâtrale occupe le plateau dans son entier, l'avant-scène est, elle le lieu du témoignage direct. Là, les monologues se succèdent et les récits narrant par le menu les sévices subis en orphelinat suivent les confidences de mères contraintes d'abandonner leur(s) enfant(s). En alternance avec ces paroles, des chansons aux accents tziganes - jouées à grand renfort d'accordéon - en appellent instamment à la charité du public. Basé sur la rupture et empêchant tout pathos, ce montage installe une distance ironique, qui pointe avec d'autant plus de force la misère sociale évoquée. À cette parole brute, sans fard, abordée avec un humour grinçant, répond la fiction théâtrale, soit le destin - et les délires - d'un jeune homme accidenté. Investissant avec des figures oniriques le plateau, cette part fictionnelle évoque à travers les délires de l'agonisant des figures mythologiques (Médée), bibliques (David et Goliath) ou encore 
littéraires (Elias Canetti, Prix nobel de littérature en 1981). Mais loin de mettre en perspective les témoignages, la convocation de ces références rend confus l'ensemble. De même, revendiquée dès l'intitulé du spectacle et régulièrement brandie comme emblème, en tant que victime d'une société responsable de sa cruauté, la figure de Médée n'apporte, elle non plus, aucun éclairage probant sur l'ensemble. Les comédiens eux-mêmes semblent empêtrés lors de ces séquences et leur éloignement contraste avec leur engagement et leur capacité à installer une tension lors des séquences documentaires. La faute, peut-être, à un texte qui pêche par souci d'exhaustivité, et demeure singulièrement dense et brouillon. Ainsi, en dépit de sa direction d'acteurs organique et de sa maîtrise réelle des dispositifs scéniques, le Sfumato ne parvient pas à faire de Medea, my Mother un travail aussi convaincant que ceux qui ont valu à la compagnie sa renommée en Bulgarie, comme à l'étranger.

\section{NOTES}

1. http://www.theatrefest-varna.org/Theatre/ENflash/index.html 